\title{
STUDY ON IMPACTS OF COVID-19 PANDEMIC RECESSION BASED ON MONTE CARLO SIMULATION*
}

\author{
Di Shang ${ }^{\mathrm{I}}$, Chang Yub ${ }^{\mathrm{b}}$, Gang Diaoc ${ }^{\mathrm{ID}}$
}

\begin{abstract}
We analyse the economic impact of the economic recession caused by the unprecedented COVID-19 pandemic by estimating the amplitude, duration and scope of influence of the recession. We employ the turning point method to extract the characteristics of the historical recessions since 1980 in 153 countries and use the information to obtain the distribution characteristics of the GDP growth rate in these countries during the current pandemic-induced recession with Monte Carlo simulation. We then make judgment on the scope of influence of this pandemic-induced recession by investigating the comovement relationship between the historical recessions in the 153 countries. The results show that this pandemic-induced recession is likely to be a severe global recession. The mean of the average simulated $\triangle \mathrm{GDP}$ of the 153 countries will plunge into a trough at $-1.16 \%$ in 2020 with a recession amplitude of approximately $4.50 \%$ and recover to the pre-crisis level of $3.29 \%$ in 2023 .
\end{abstract}

Keywords: COVID-19 pandemic, economic recession, GDP growth rate forecasting, turning points, Monte Carlo simulation

JEL Classification: E30, F60

\section{Introduction}

The year 2020 is doomed to be an unusual year due to the outbreak of the COVID-19 pandemic. With the first reported death on 9 January in China, the numbers of COVID-19 cases and deaths have soared globally. According to the World Health Organization

* This research was supported by the Ministry of Education Humanities and Social Sciences Fund Project No. 19JC790020; and the National Natural Science Foundation of China No. 71873016. Corresponding author: Gang Diao (diaogang82@126.com)

a School of Economics and Management, Harbin Institute of Technology (Shenzhen), Shenzhen, Guangdong, China

b School of Economics and Management, Beijing Forestry University, Beijing, China

c Business School, Lishui University, Lishui, Zhejiang, China

Emails: shangdi0215@163.com; changyu@bjfu.edu.cn; diaogang82@126.com 
(WHO), by 21 September 2020, COVID-19 was detected in 216 countries and has led to over 30 million confirmed infections and nearly 960 thousand deaths. The rapid spread of the coronavirus in many countries is overwhelming their health systems. Due to the highly contagious nature of the virus and inexorable implications of its explosive spread during the "acceleration phase" of the pandemic, the governments in the affected countries and regions have imposed draconian public health containment measures, including lockdowns, social distancing, school and business closures, home confinement and travel bans, to control the pandemic. These measures, while necessary, are bound to cause severe damage to the economy, and a direct loss of GDP is unavoidable (Galí, 2020; Gourinchas, 2020; Weder di Mauro, 2020; Makridis and Hartley, 2020; Ramelli and Wagner, 2020). The economic impact is already visible in the countries most affected by the COVID-19 outbreak. The large-scale lockdown measures brought production and consumption in China almost to a standstill. According to Bloomberg, industrial production in China fell by $13.5 \%$ in January and February versus a median estimate of $-3 \%$, which is much higher than previously expected (Baldwin and Weder di Mauro, 2020). It is certain that a large economic recession is upcoming for obvious reasons, but the magnitude and persistence of the recession is still very uncertain.

The pandemic itself and the related containment measures in combination almost plunge the economy into a sudden stop (Gourinchas, 2020). Business disruptions have lowered production, reduced consumer purchasing power and weakened consumption of goods and services, creating both supply and demand shocks. The loss may be further amplified if the sharp decline in output and economic activities leads to bankruptcies and large-scale layoffs, which will expose the financial system to a high risk of loan defaults and increase unemployment. Thus, the whole economy and society are facing an extreme situation, where swift and well-targeted policies and measures that are commensurate to the size of the challenge are needed to minimize the economic impact of the coronavirus crisis. To do so, the governments and other economic participants need information on the recession to formulate proper and effective fiscal policies and management strategies. The key economic questions of interest include: How bad will the recession get? How long will the recession last? How far will it spread? However, predictions of the economic impact of the COVID-19 pandemic are extremely difficult because what we are facing is a rare joint health and economic crisis of high uncertainty. Different from previous economic recessions, it hit the global economy at the same time, including the economic giants of the G7 countries and China, and the economic disruptions are widely spread, hitting many sectors all at once. Moreover, the spread of the virus, the policy responses and individual behaviours are unknown, adding to the uncertainties of the economic impact. With no benchmark in the recent history and vast uncertainties 
involved, it is difficult to predict the impact of the current recession. Given the need for more information for policy formulation, this study intends to provide insight into the characteristics of this pandemic-induced recession by estimating the depth, duration and scope of influence of the recession.

\section{Literature Review}

Prior work on the evaluation of the impact of economic recessions has concentrated on the measurement of the amplitude and duration of recessions. Defined as a significant decline in the economic activity spread across the country, recession is usually investigated by various macroeconomic indicators such as GDP growth rate, unemployment, industrial production, real personal income, stock market indices, trade volumes and so on (Drechsel and Scheufele, 2012; Mazurek and Mielcová, 2013). Among them, GDP growth rate is the most widely used indicator in the analysis of recessions, because it represents one of the most important characteristics of an overall economy (Frankel and Saravelos, 2012; Mazurek and Mielcová, 2013; Dimitras et al., 2015). Graphs of data on macroeconomic indicators are capable of providing essential information on the characteristics of the economy; thus, a number of studies adopt graphical approach to analyse the economic impact of recessions (Gascon, 2009; Claessens et al., 2009; Cardarelli et al., 2011). Gascon (2009) compared six recessions by plotting the charts of four main economic indicators and described the recessions qualitatively as "mild" or "severe" in terms of both the depth and duration of the recessions, where the 2008 financial crisis was depicted as the most severe recession in the past 40 years but milder than the Great Depression. Claessens et al. (2009) and Carstensen et al. (2020) detected and analysed the recessions in 21 OECD countries over 1960-2007 and in Germany over 1991-2016, respectively, by identifying the turning points of the recessions. Mazurek and Mielcová (2013) regarded recession depth and duration to be the most important characteristics concerning recession magnitude and introduced a quantitative recession magnitude scale calculated as a function of the decline in GDP growth rate and the duration of recession. Most of the studies describe the whole process as a V-shaped or U-shaped recession and recovery process, where the recession depth and duration constitute the two main determinants of the curve shape.

In face of the expanding pandemic-induced recession, economists have made judgment on the magnitude and shape of the recession to assess its economic impact. Based on a comparison of major indicators and an analysis of the multiple shocks in the global supply and demand chains as a result of the drastic containment measures, Gopinath (2020) and Gourinchas (2020) believed that the economic decline in this recession would be larger than that in the 2008 Great Financial Crisis. Odendahl and Springford (2020), 
on the other hand, suggested that the long-term effects of the economic disruptions induced by the pandemic would be less severe and the economy would return to the usual trajectory in a short term with proper government policies and interventions. Gourinchas (2020) and Baldwin and Weder di Mauro (2020) further related the recession curve with the pandemic curve and pointed out that the containment policies which could flatten the pandemic curve would inevitably steepen the depth of the recession. Regarding the duration of the current recession, Panizza (2020) indicated that it was more likely to observe a sharp decline and quick recovery - V-shaped recession - in countries with more fiscal space and higher trend growth, whereas Mann (2020) stated that this recession would probably be U-shaped with longer duration at the global level. So far, most of the existing research on the economic impacts of the current recession has mainly discussed the possible trend and magnitude of this recession and arrived at varied conclusions.

The rapid development of globalization makes the world economy more and more connected. Since economic fluctuations in one country or region will be transmitted to other countries or regions through international trade and interactions, the influence scope has become one of the critical issues in the analysis of the impacts of economic recessions. Da Silva et al. (2016) investigated the 2008 financial crisis and its influence scope by qualifying the cross-correlation between the adjusted closing index of the G7 countries and concluded that the effect of the crisis spread to almost all these countries. Kim et al. (2015) identified the transmission mechanisms of the 2008 global financial crisis by estimating conditional correlations of financial asset returns across countries using multivariate GARCH models. Dewandaru et al. (2018) employed wavelet analysis to identify the co-movement pattern on selected European equity markets during nine major crises and found strong evidence of financial contagion of the crises across the region. In the case of the present coronavirus recession, most economists believe that it is very likely to become a global economic recession (Fernandes, 2020; Oziliand and Arun, 2020; Beck, 2020; Gourinchas, 2020). As COVID-19 had spread to over 200 countries, it has hit all the major economies of the world almost at the same time and resulted in concurrent recession on a global scale, whereas most previous economic recessions originated from one country or economy with a specific economic event and then were transmitted to other countries and economies. Therefore, what we are dealing with this time is a situation very different from the previous economic recessions, which calls for special attention to its influence scope.

This study predicts the major characteristics of the economic recession induced by the unexpected external shock of COVID-19 so as to provide reference and basis for the formulation of macroeconomic policies to mitigate the economic impacts of the recession. Since no similar event exists in recent history as a benchmark, it would 
be inappropriate to use existing parametric models to predict the current recession. Thus, we adopt the more flexible and more intuitive graphical approach of the turning point method to capture the main characteristics of all the historical recessions since 1980, including the recession amplitude and the duration of the recession and recovery phases, and apply them to a prediction of the COVID-19 recession. We simulate the evolution path of the economic recession from a statistical probability perspective based on the information extracted from the historical recessions and analyse the distribution characteristics of the GDP growth rate during the recession. In this way, we effectively yield simulations of the recession that basically cover the major possible recession scenarios in a more accurate way, which can assist the policymakers in acquiring a more thorough understanding of all the possible outcomes of the recession.

The rest of the paper is organized as follows. Section 3 describes the data and methods applied in this study. Section 4 provides the analysis and explains the results. Section 5 discusses the results and Section 6 concludes the study.

\section{Data and Methodology}

\subsection{Data}

The original data used in this study are yearly GDP growth rates (2010 base) obtained from the World Bank Database (2020). We collected the GDP growth rates ( $\triangle$ GDP) over a time span of 39 years between 1980 to 2018 for 179 countries, a total of 6,092 observations. Since the $\Delta$ GDP of the 179 countries were not all available for the whole period, countries with no more than 25 available observations in 7 their $\Delta$ GDP series were excluded from the data set to ensure the feasibility of the following econometric analysis. Then the $\Delta$ GDP series for 153 countries remained in the final data set, a total of 5,719 observations. See Appendix A for further details and summary descriptive statistics of the data set.

\subsection{Methodology}

\subsubsection{Turning point method}

For the detection and measurement of economic recessions since 1980, this study followed the work of Hardings and Pagan (2002), which studied business cycles by dissecting the turning points in the series of $\triangle \mathrm{GDP}$. The turning point method is a graphical approach that was first proposed by Burns and Mitchell (1946) to describe the characteristics of business cycles. A typical business cycle consists of two phases of contraction and expansion, with turning points (peaks and troughs) present at the transition of the two phases. Contraction phases are characterized by generally declining $\Delta$ GDP and expansion 
phases by generally increasing $\triangle$ GDP. A peak is located at the turning point from the expansion phase to the contraction phase, whereas a trough is located at the turning point from the contraction phase to the expansion phase. Translating the ocular judgement into an algorithm, a local peak in the year $t$ is defined as $\Delta G D P_{t}>\Delta G D P_{t \pm 1}$, and a local trough in the year $t$ is defined as $\triangle G D P_{t}<\Delta G D P_{t \pm 1}$. With turning points located, specific business cycles can be identified with two consecutive peaks or troughs (Burns and Mitchell, 1946; Rossen, 2015). Hardings and Pagan (2002) extended the turning point method by depicting a phase as a triangle formed by turning points, which was capable of capturing more characteristics of business cycles (see Appendix B for a detailed explanation of the turning point method). Once the turning points are identified, the shape of the evolution path of the business cycle can be approximated with a triangle and the following characteristics of the cycles can be calculated: the number of cycles (peak-to-peak or trough-to-trough), durations of contraction and expansion phases, duration of full cycles and amplitudes of contraction and expansion phases (mean, minimum and maximum).

Similar to typical business cycles, which consist of two phases of contraction and expansion, economic recessions caused by unexpected shocks always go through two phases of recession and recovery with a trough present at the turning point from the recession phase to the recovery phase (Carstensen et al., 2020). Therefore, an economic recession caused by unexpected shocks can also be proxied by a triangle, and thereby the triangle approximation based on the turning point method should also be applicable to analysing the characteristics of a recession. Figure 1 explains the application of the turning point method in detecting and evaluating the recession induced by the 2008 global financial crisis in a selected country. The $\triangle$ GDP used in the analysis is processed with the Christiano-Fitzgerald full sample asymmetric filter to remove the trends and random fluctuations in the series, making the sequence smoother. The whole recession process is proxied by the triangle $A B D$, with the triangle $A B C$ corresponding to the recession phase and the triangle $A C D$ to the recovery phase. $B$ denotes the beginning of the recession, $D$ denotes the end of the recession, and $A$ denotes the trough of the recession. The height of the triangle $A B D(A C)$ is the amplitude of the recession, and the base of the triangle $A B D(B D)$ is the overall duration of the recession. Considering the two phases of recession and recovery as two triangles, the base of the triangle $A B C(B C)$ is the duration of the recession phase and the base of the triangle $A C D(C D)$ is the duration of the recovery phase. Moreover, the hypotenuse $A B$ represents the approximated path of the recession phase and the hypotenuse $A D$ represents the approximated path of the recovery phase. The area of the triangle $A B D$ is an approximation to the cumulative economic losses caused by the 2008 financial crisis. 


\section{Figure 1: Illustration of turning point method}

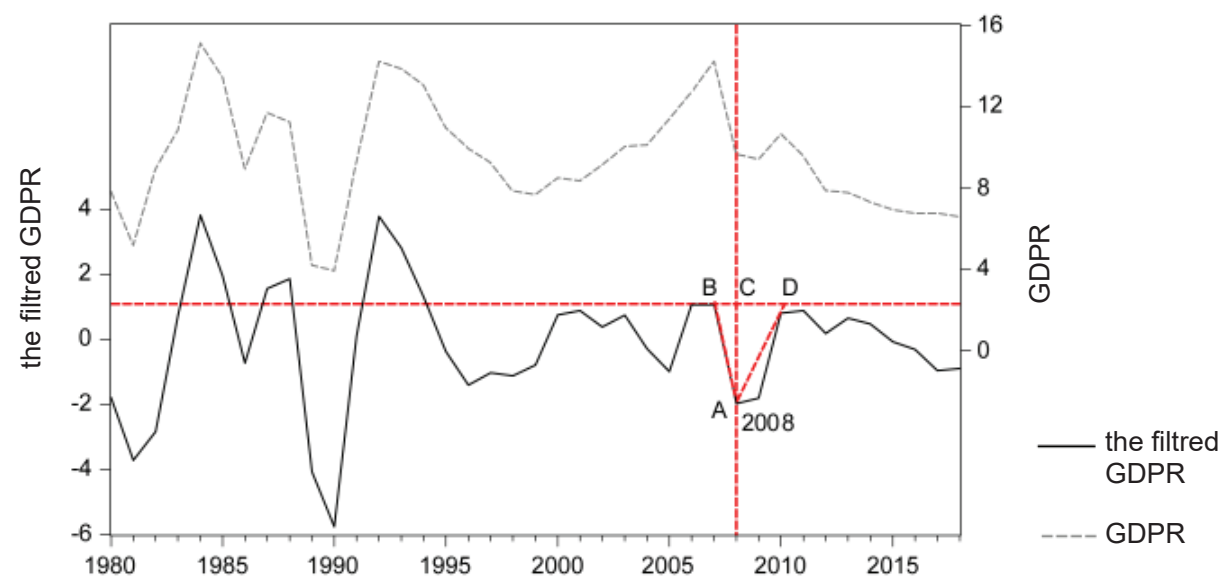

Source: GDPR is collected from World Bank Database (2020) and the filtered GDPR is from own calculation.

\subsubsection{Measurement of co-movement between recessions}

Co-movement between recessions can be measured by the degree of concordance between two time series $Y_{i, t}$ and $Y_{j, t}$, which is quantified by the proportion of time that both series are simultaneously in the same phase (Harding and Pagan, 2002; Roberts, 2009). Thus, the concordance statistic is calculated as:

$$
C_{i j}=T^{-1}\left\{\sum_{t=1}^{T}\left(S_{i, t} \times S_{j, t}\right)+\sum_{t=1}^{T}\left(1-S_{i, t}\right) \times\left(1-S_{j, t}\right)\right\}
$$

where $T$ is the sample size of the time series and $\mathrm{S}_{i, t}$ a binary time series that is equal to 1 if the series $Y_{i, t}$ is in the recovery phase and equal to 0 if the series $Y_{i, t}$ is in the recession phase. This statistic is equal to one if both series $Y_{i, t}$, and $Y_{j, t}$ are in the same phase at any time. It has the advantage that it is independent of the selected turning points because it is unaffected by the amplitudes (McDermott et al., 1999).

To test the statistical significance of this statistic, Harding and Pagan (2006) suggested a simple $t$-test based on the correlation coefficient $(\rho)$ between the series $S_{i, t}$ and $S_{i, t}$ Under the null hypothesis of no concordance, this coefficient is equal to zero. The following regression is used in order to estimate $\rho$ and calculate its heteroscedastic and autocorrelation corrected $t$-statistic:

$$
\frac{S_{i, t}}{\hat{\sigma}_{s_{i}} \times \hat{\sigma}_{s_{j}}}=\alpha+\rho \frac{S_{j, t}}{\hat{\sigma}_{s_{i}} \times \hat{\sigma}_{s_{j}}}+e_{t}
$$

where $\hat{\sigma}_{s i}$ and $\hat{\sigma}_{s j}$ are the estimated standard deviation of $S_{i, t}$ and $S_{j, t}$. 


\subsubsection{Simulation of pandemic-induced economic recession}

Based on the characteristics of the historical economic recessions in the 153 countries, this study uses Monte Carlo simulation to predict the impact of the COVID-19 pandemic on global economic growth. This study assumes that the amplitude and duration of recession and recovery phases all follow a triangular distribution. Triangular distribution is defined by three values of the minimum, maximum and most likely value and has the advantage of being able to describe the characteristics of a random variable for which there are only limited sample data and distribution information. First, the calculated results of the characteristics of the historical economic recessions are used to determine the parameters of the triangular distribution, based on which the values of the amplitude, duration of the recession phase and duration of the recovery phase of this pandemic-induced recession are randomly chosen in the simulation. Then, the three randomly chosen values are used to locate the turning point of the current recession ${ }^{1}$, and the $\Delta \mathrm{GDP}$ of the year at the start and end of the recession are determined by the combination forecasting of the forecast results from the ETS and ARMA models ${ }^{2}$. Finally, the remaining $\triangle$ GDP other than the ones identified by the turning point method are calculated using the spline interpolation method. This study performs the simulation 1,000 times for each of the 153 countries to obtain the distribution of the $\triangle \mathrm{GDP}$ during this pandemic-induced recession.

\section{Results}

\subsection{Methodology validity analysis}

In order to examine the reliability and applicability of the turning point method employed in this study, we analysed the Great Financial Crisis caused by the US subprime mortgage crisis in 2008 with this method. We first identified all the economic recessions during 1980-2007 and acquired information on the durations of recession and recovery phases (mean, minimum and maximum) and the recession amplitude (mean, minimum and maximum). Then, we applied the asymmetric filtering method to extract the trend of the $\Delta$ GDP and make the prediction. Finally, we performed the Monte Carlo simulations to simulate the Great Financial Crisis, and obtained the distribution characteristics of the $\Delta \mathrm{GDP}$ by combining

$1 \Delta \mathrm{GDP}$ at the turning point $=\Delta \mathrm{GDP}$ under combination forecasting of the forecast results from the ETS and ARMA models without consideration of the pandemic-induced recession - recession amplitude.

$2 x_{-} f=w_{1} x_{-} A R M A_{-} f+w_{2} \times x_{-} E T S_{-} f, w_{1}=\frac{1 / e_{1}}{1 / e_{1}+1 / e_{2}}, w_{2}=\frac{1 / e_{2}}{1 / e_{1}+1 / e_{2}}, e_{1}=\left(x-x_{-} A R M A_{-} f\right)^{2}$, $e_{2}=\left(x-x_{-} E T S_{-} f\right)^{2}$. 
the simulation results with the trend forecast results. Since the causes of economic recessions are diverse and differences exist in the recession degrees, this study calculated the distribution of the $\Delta$ GDP during the Great Financial Crisis to provide a more comprehensive view of the recession. Unlike existing studies, this study does not use the mean of the simulated $\Delta \mathrm{GDP}$ as the final forecast result.

This study illustrated the locations of the real values of the $\triangle \mathrm{GDP}$ in the distributions of the simulated $\triangle \mathrm{GDP}$ of the G7 countries and China during the two most severely affected years of the Great Financial Crisis (2008 and 2009) (see Appendix C for detailed results). The results show that in the occurrence year of the Great Financial Crisis, the real values of the $\Delta \mathrm{GDP}$ of the eight countries are mostly concentrated on the right side of the medians of the simulated $\Delta$ GDP. In 2009, the effects of the Great Financial Crisis gradually appeared and the distributions of the simulated $\Delta \mathrm{GDP}$ of the eight countries became more scattered, with the real $\Delta \mathrm{GDP}$ of the G7 countries mainly concentrated at the left end of their simulated $\triangle$ GDP distributions and that of China located at the right end of its simulated $\Delta$ GDP distribution. From the perspective of the frequency of appearance, the real values of the $\Delta$ GDP all appear in the higher-frequency part of the simulated $\Delta$ GDP distribution, which demonstrates that studying the distribution of the simulated economic recession is of important reference value for understanding the economic changes.

The simulation results of the economic impact of the Great Financial Crisis in 2008 show that the turning point method employed in this study accurately reflects the major characteristics of the economic recession and provides important reference value for the prediction of the impact of emergencies on the economy. The simulation results of the Great Financial Crisis demonstrate that the method calculates a more accurate distribution of the $\Delta$ GDP during the economic recessions caused by emergencies, and the distribution covers various situations of economic recessions and provides information for judging the impact of economic recessions. Meanwhile, the comparison between the distribution of simulated $\Delta \mathrm{GDP}$ and the real values of the $\Delta \mathrm{GDP}$ shows that the method manages to depict the change characteristics of the economic recessions in each country, viz. the locations of the real values of the $\triangle \mathrm{GDP}$ in the distribution (left tail or right tail), and reflects whether the future expectations are pessimistic or optimistic. Since there exists great uncertainty in the amplitude and duration of economic recessions caused by emergencies, it is difficult to accurately predict the changes in $\triangle$ GDP with traditional parameter methods. Although the method employed in this study cannot precisely predict the $\Delta \mathrm{GDP}$, it can accurately calculate the range of the $\Delta \mathrm{GDP}$ during the economic recession caused by emergencies. 
Figure 2: Results of forecast error analysis

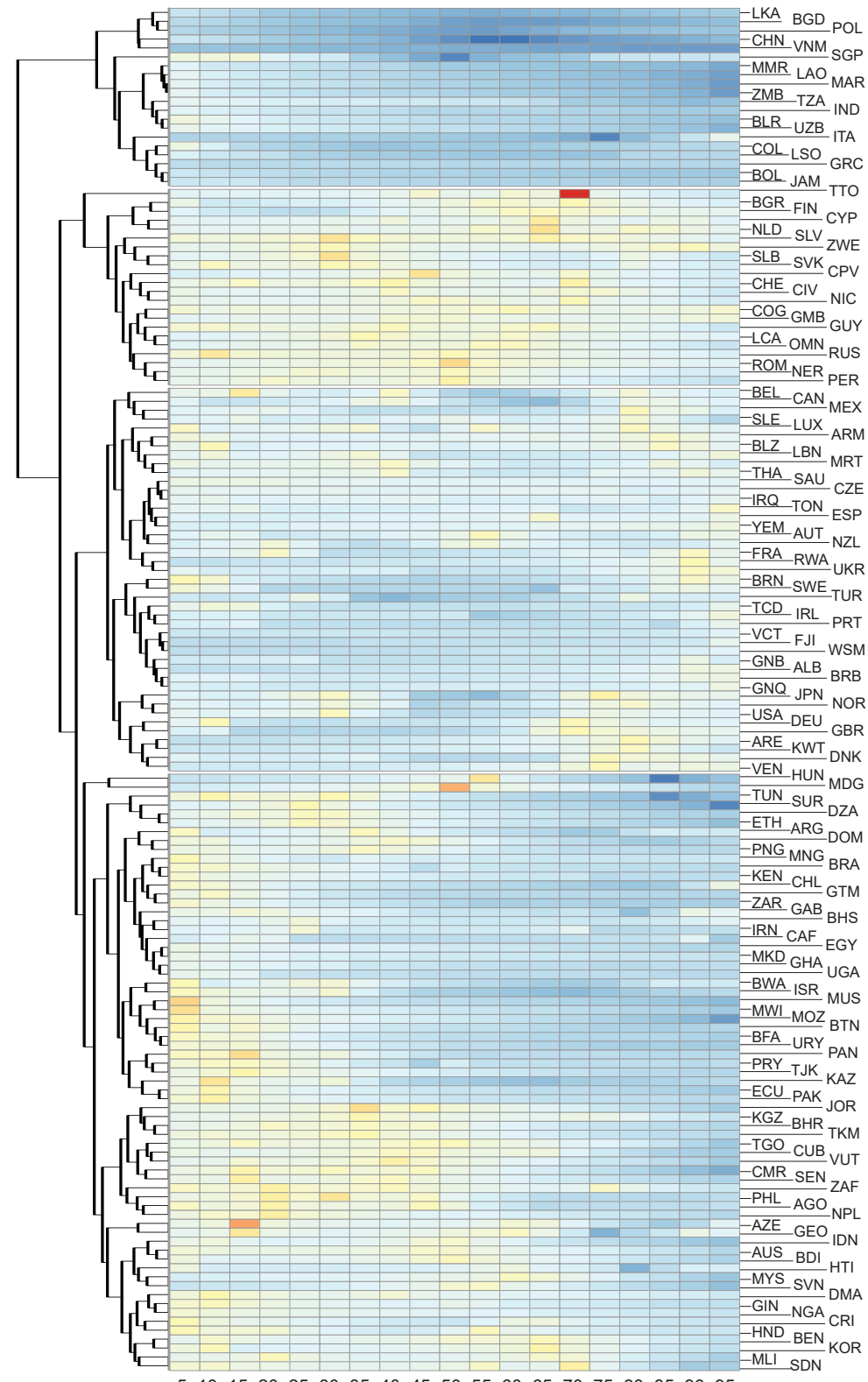

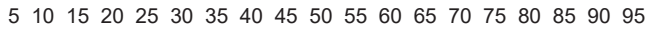

Note: The horizontal axis is the quantiles of the simulation results.

Source: Own calculation 


\subsection{Characteristics of historical economic recessions}

Figure 3: Distribution of the major characteristics of the historical recessions during 1980-2018 in 153 countries
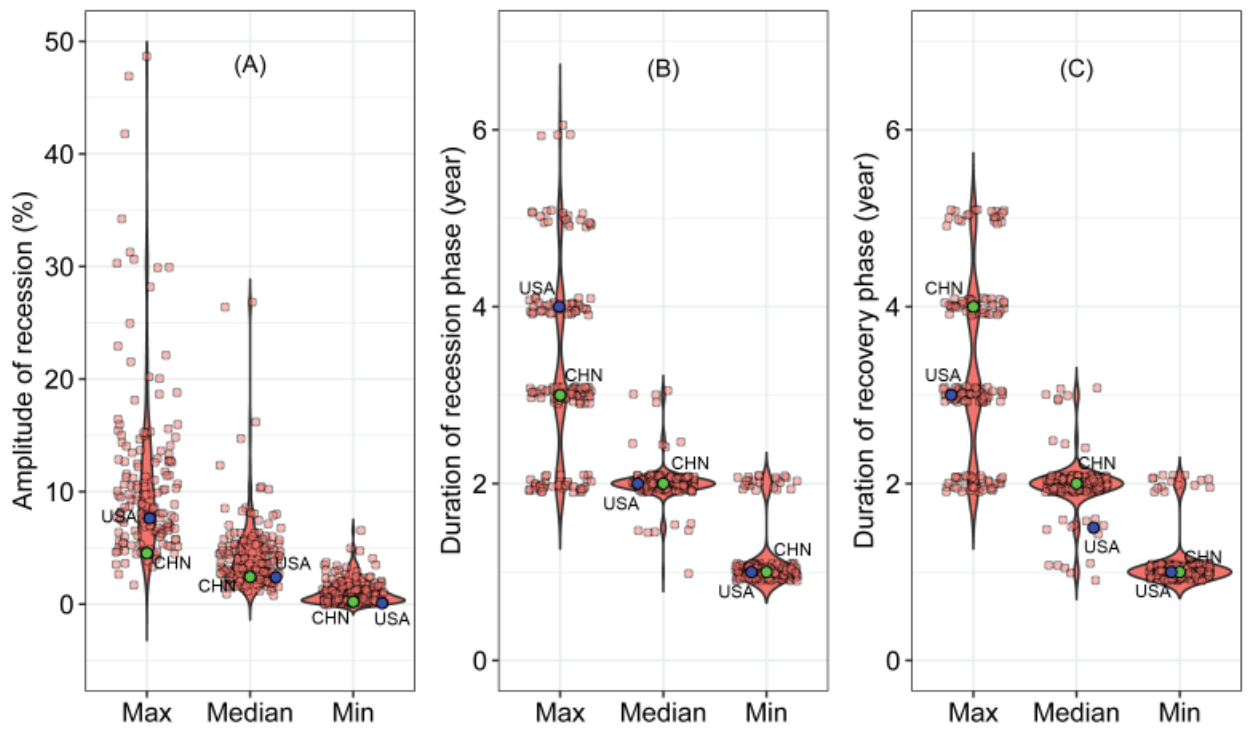

Source: Own calculation

We first employed an asymmetric filter to isolate the cyclical component of the $\Delta$ GDP series by specifying a range of 3 to 10 years for their duration. Then we detected all the historical recessions since 1980 for the 153 countries based on the turning point method and depicted the three major characteristics of the recessions in each country in Figure 3, including the amplitude of the recession, the duration of the recession phase and the duration of the recovery phase. Since the distributions of the three characteristics of the historical recessions in the 153 countries deviate significantly from normal distribution, we used median, maximum value and minimum value to provide the general description of characteristics of the historical recessions in each country. For the amplitude of the recessions in each country, the medians lie between $1 \%$ and $27 \%$ and concentrate around $3 \%$. The maximum values are more widely distributed from $2 \%$ to $48 \%^{3}$ and concentrate around $7 \%$, whereas the minimum values are more tightly distributed from of $1 \%$ to $7 \%$ and concentrate around $1 \%$. In terms of the duration of the recession phases

3 The outlier of $117 \%$ from Equatorial Guinea is excluded from the statistics due to the extreme situation of the specific recession. 
in each country, the medians range from 1 to 3 years, where over $90 \%$ exhibit 2 years. The maximum values present a four-peak distribution and most lie around 2 years, 3 years, 4 years and 5 years, while the minimum values exhibit a two-peak distribution and concentrate around 1 year and 2 years. The distributions of the medians and maximum and minimum values of the duration of the recovery phases in each country present a pattern similar to those of the duration of the recession phases, with medians located around 2 years, maximum values distributed around fours peaks at 2 years, 3 years, 4 years and 5 years and minimum values distributed around two peaks at 1 year and 2 years.

Since the G7 countries and China are among the largest economies in the world, the recessions of which could have a significant influence on the global economy, we took a special look at the characteristics of their recessions. We detected 7 recessions in the United States (USA), 8 recessions in China ( $\mathrm{CHN}$ ) and the United Kingdom (GBR), 9 recessions in Canada (CAN), Germany (DEU), France (FRA) and Japan (JPN), and 10 recessions in Italy (ITA) (see Appendix D for detailed results). The medians of the amplitude of the historical recessions in the eight countries, which denote the overall severity of all the historical recessions since 1980 in these countries, range from $1.49 \%$ to $2.56 \%$, while the medians of the recession amplitude in France, Italy, the United Kingdom and Japan lie around $1.50 \%$ and those in China, the United States, Canada and Germany lie around $2.50 \%$. The maximum values of the amplitude of the historical recessions in these countries vary within a wider range from $4.45 \%$ to $8.13 \%$, where the slightest recession amplitude occurs in Japan and the most severe one is shown in Germany. The minimum values of the amplitude of the historical recessions in these countries are more approximate and are all below 1\%. As for the duration of the recession phases in the G7 countries and China, the median is 2 years and the minimum value is 1 year in all the eight countries, whereas the maximum values range from 2 to 5 years, while Italy exhibits the smallest maximum value of 2 years and Japan exhibits the largest maximum value of 5 years. Regarding the duration of the recovery phases, the medians in all the G7 countries are 2 years, whereas China exhibits a shorter duration of 1.5 years. The minimum values are all 1 year in the eight countries, and the maximum values are 3 years in most G7 countries and China except for 4 years in Germany and the United States and 2 years in Italy.

\subsection{Monte Carlo simulation results}

Based on the information on the characteristics of the historical recessions identified by the turning point method, we adopted a triangular distribution to simulate the $\Delta \mathrm{GDP}$ in the 153 countries during the current recession caused by the COVID-19 pandemic using Monte Carlo simulation. Figure 4 describes the distribution of the global $\Delta$ GDP during the period 2019-2025, which covers the duration of the simulated recession for almost all 
the countries. It can be seen that the average simulated $\Delta \mathrm{GDP}$ of the 153 countries during the recession presents an asymmetric $\mathrm{V}$-shaped recession with a longer recovery phase, where the turning point occurs in 2020. The interquartile range of the average simulated $\triangle \mathrm{GDP}$ of the 153 countries in 2020 ranges from $-2.63 \%$ to $1.20 \%$, with a median of $-0.46 \%$. The mean of the average simulated $\Delta$ GDP of the 153 countries declines from $3.29 \%$ in 2019 to $-1.16 \%$ in 2020 with a recession amplitude of approximately $4.50 \%$. Thus, there is a severe global GDP contraction in 2020. Then the global economy begins to recover with an increasing $\triangle \mathrm{GDP}$ from 2021 and the mean of the average simulated $\Delta$ GDP recovers to the pre-crisis level of $3.29 \%$ in 2023.

\section{Figure 4: Simulation results of global $\triangle$ GDP in 2019-2025}

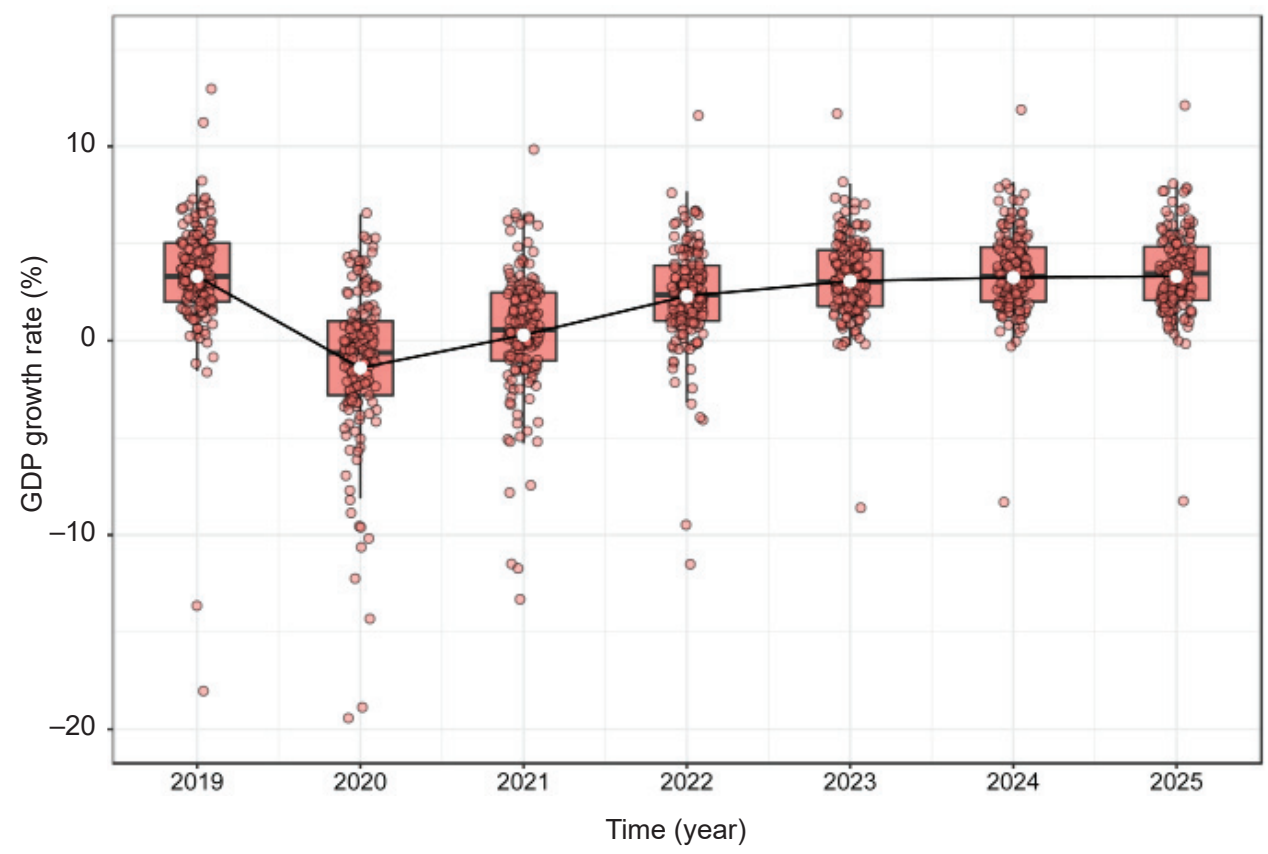

Notes: The dots in the boxplot denote the average simulated $\triangle$ GDP of the 153 countries calculated as the mean of the simulated $\triangle G D P$ in each country, and the bar in the boxplot denotes the median of the dots. The white circles on the solid line denote the mean of the average simulated $\triangle G D P$ of the 153 countries that were calculated as the mean of the dots.

Source: Own calculation

Figure 5 demonstrates the distributions of the simulated $\triangle \mathrm{GDP}$ in the period from 2019 to 2025 in the G7 countries and China. For the United States, the trough of the recession occurs in 2020. The interquartile range of the simulated $\Delta$ GDP is from 
$-0.23 \%$ to $0.95 \%$, with a $20 \%$ probability of negative $\Delta$ GDP in 2020 . The simulated $\Delta$ GDP in 2021 and 2022 both exhibit a bimodal distribution. The two peaks in the distribution of the simulated $\Delta \mathrm{GDP}$ in 2021 lie around $0.80 \%$ and $2.80 \%$ with more of the simulated $\Delta$ GDP concentrating around $0.80 \%$, suggesting a signal of economic recovery, whereas the two peaks in the distribution of simulated $\Delta$ GDP in 2022 lie around $1.00 \%$ and $2.80 \%$ with more of the simulated $\Delta$ GDP concentrating around $2.80 \%$, indicating a stronger economic recovery in 2022. The distributions of the simulated $\Delta$ GDP in 2023 to 2025 suggest that the $\Delta$ GDP recovers to the pre-crisis level in 2023 and continues to increase thereafter. Regarding the simulation results for China, like in the United States, the trough of the recession also occurs in 2020, but all of the simulated $\Delta$ GDP in 2020 of China lie above zero and concentrate around 5\%, with an interquartile range of $3.97 \%$ to $5.82 \%$. The distribution of the simulated $\triangle \mathrm{GDP}$ in 2021 is negatively skewed, with relatively more simulated $\triangle \mathrm{GDP}$ concentrating around $8 \%$. The strong recovery momentum continues from 2021 to 2022 in China, shown as a high probability of an 8\% $\Delta$ GDP in 2022, which is even higher than the pre-crisis level of $7.12 \%$ in 2019 . The distributions of the simulated $\Delta$ GDP in 2023 to 2025 suggest that the economy in China keeps increasing at a relatively stable growth rate around $8 \%$. In terms of the amplitude of this pandemic-induced recession, China suffers a more severe decline of over 2 percentage points from $7.12 \%$ in 2019 to $4.97 \%$ in 2020 compared to a decline of about 1.83 percentage points in the United States from $2.21 \%$ in 2019 to $0.38 \%$ in $2020^{4}$. On the other hand, China shows a stronger recovery momentum and turns to an expansion trajectory more quickly than the United States.

Among the rest of the G7 countries, the trough of this recession occurs in 2020 for the United Kingdom, Germany, Italy, Canada and France and in 2021 for Japan. The $\Delta$ GDP in these countries in 2020 present a high probability of negative values, with most of the simulated $\Delta \mathrm{GDP}$ in Germany and Japan concentrating around $-2 \%$, in the United Kingdom and Canada around $-1 \%$, and in France around 0 . The simulated $\Delta$ GDP in Italy in 2020 is distributed flatly within the range from $-5 \%$ to 0 . Except Italy, the simulated $\Delta$ GDP in the other five countries in 2021 all exhibit bimodal distributions, and show a signal of recovery in the United Kingdom, Germany, Italy and Canada and further recession in France and Japan. The distribution of the simulated $\Delta$ GDP in Italy in 2021 presents a relatively high probability of zero $\Delta \mathrm{GDP}$, which also signals recovery of its economy. Except Italy, the simulated $\triangle \mathrm{GDP}$ in the other countries all recover to the pre-crisis level by 2023 and then remain at the same level by 2025 . Although the $\Delta$ GDP in Italy begins to recover in 2021, it fails to recover to its pre-crisis level and remains negative by 2025 .

4 The amplitude of the recession is calculated as the difference between the median of the simulated $\Delta$ GDP in 2019 and the median of the simulated $\Delta$ GDP in the year of trough, since most of the distributions are skewed. 
The most severe recession amplitude occurs in Japan with a decline of 3.80 percentage points from $1.21 \%$ in 2019 to $-2.59 \%$ in 2021 , and the mildest recession amplitude occurs in France with a decline of 1.67 p.p. from $1.55 \%$ in 2019 to $-0.12 \%$ in 2020 .

Figure 5: Simulation results of $\triangle$ GDP for G7 countries and China for 2019-2025
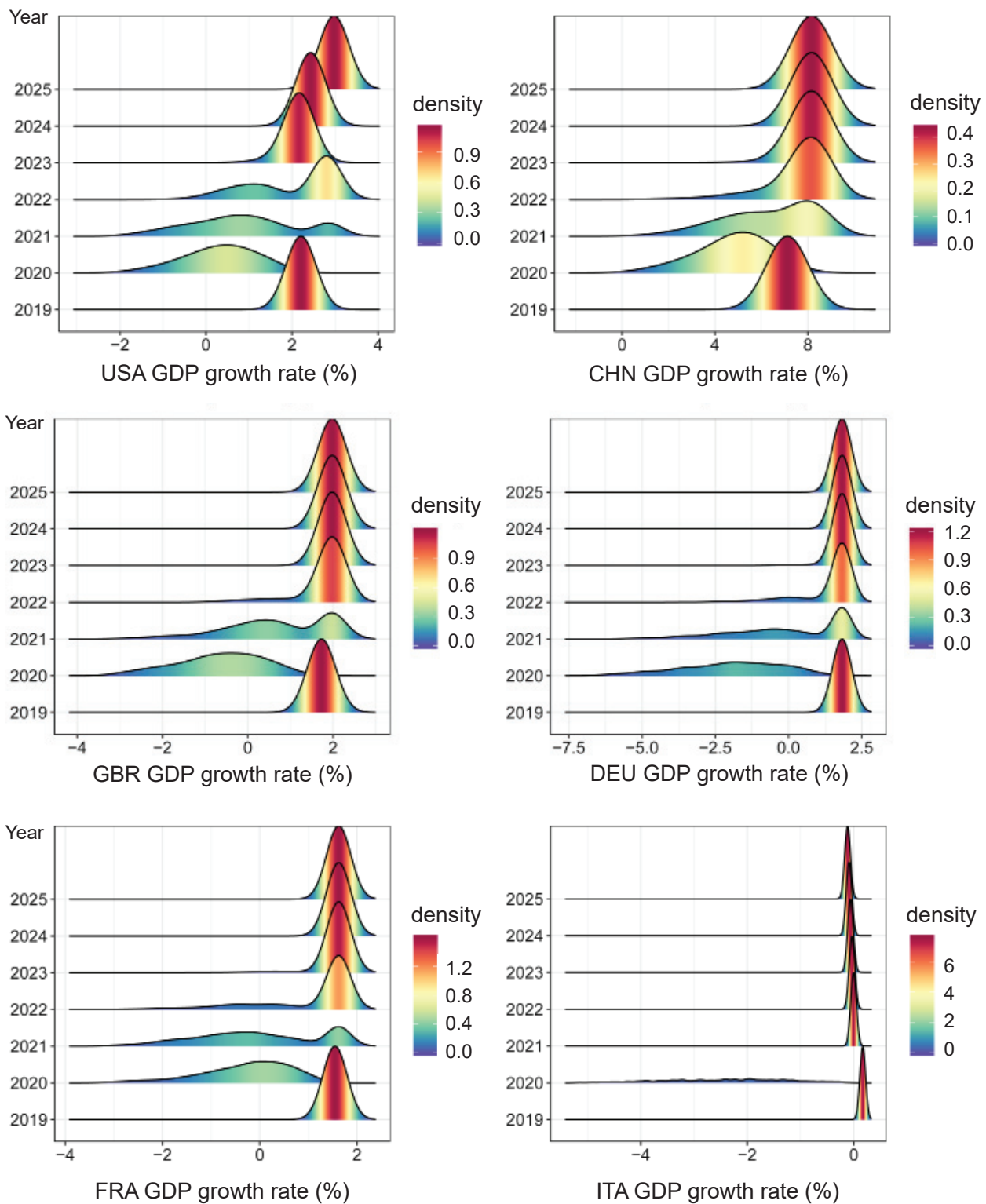

ITA GDP growth rate (\%) 


\section{Figure 5: Continuation}
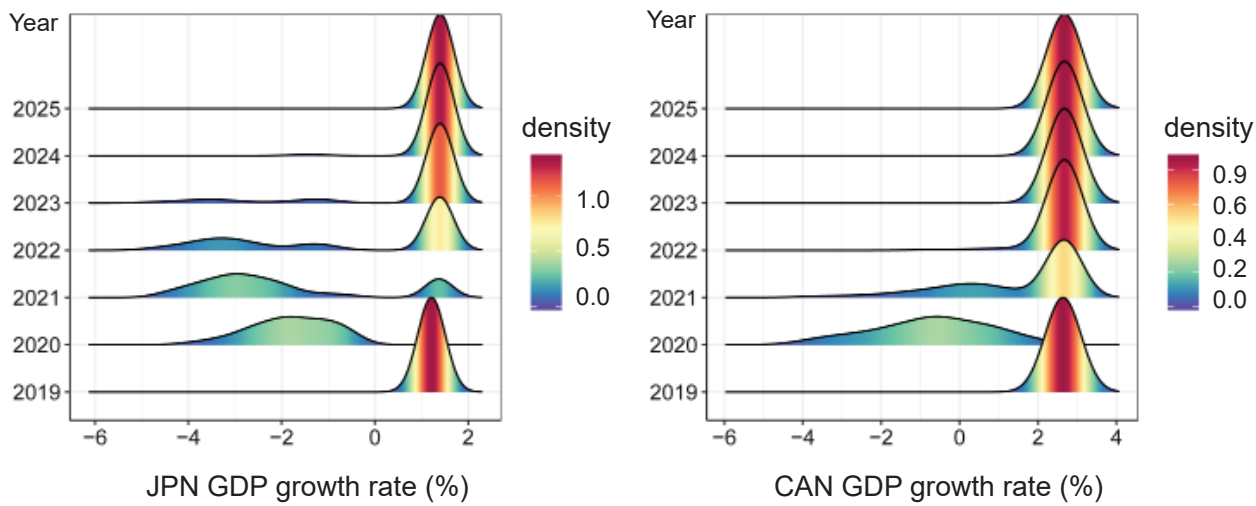

Source: Own calculation

\subsection{Influence scope of recession caused by pandemic}

As mentioned before, the influence scope of economic recessions can be measured by the co-movement between different economies; thus, we first calculated the degree of concordance between the recessions in the 153 countries based on Eqs. (1) and (2) (see Appendix E for the calculation results of concordance statistics). The correlation coefficients indicate a strong overall co-movement regarding the duration and timing of the recession phases across the countries.

The co-movement network of global recessions is calculated based on the calculated correlation coefficients that are significant at the 5\% level. Figure 6 demonstrates the network and depicts the co-movement relationship between the recessions across the 153 countries. The size of the nodes in the network reflects the degree of the node. The larger the size of the node, the greater the value of the node degree, and the wider the influence scope of the recessions in the country. The degree of the nodes in the co-movement network of global recessions ranges from 6 to 49, with a mean of 24.26 and the average neighbour degree ranges from 17.83 to 35.32 , with a mean of 27.50 . There is also a positive relationship between the node degree and the average neighbour degree, viz. the greater the node degree, the greater the average neighbour degree (see Appendix F for an illustration). This is consistent with the characteristics of node location shown in Figure 6. It can be seen that the countries with high node degrees, such as the top five of Canada (CAN), Colombia (COL), United Arab Emirates (ARE), Belgium (BEL) and Gabon (GAB), are mostly located in the lower left corner of the network, presenting the characteristics of aggregation. Moreover, the co-movement network exhibits a high 
level of connectivity, with the existence of a giant component in the network that connects all the 153 countries. The average path length in the network is only 1.93 and the maximum path length is merely 3 , indicating that the network presents a high level of aggregation. Thus, the co-movement network of global recessions is a small-world network, suggesting that the economic recession in an individual country is easily transmitted to other countries and has a wide influence scope.

\section{Figure 6: Co-movement network of global recessions}

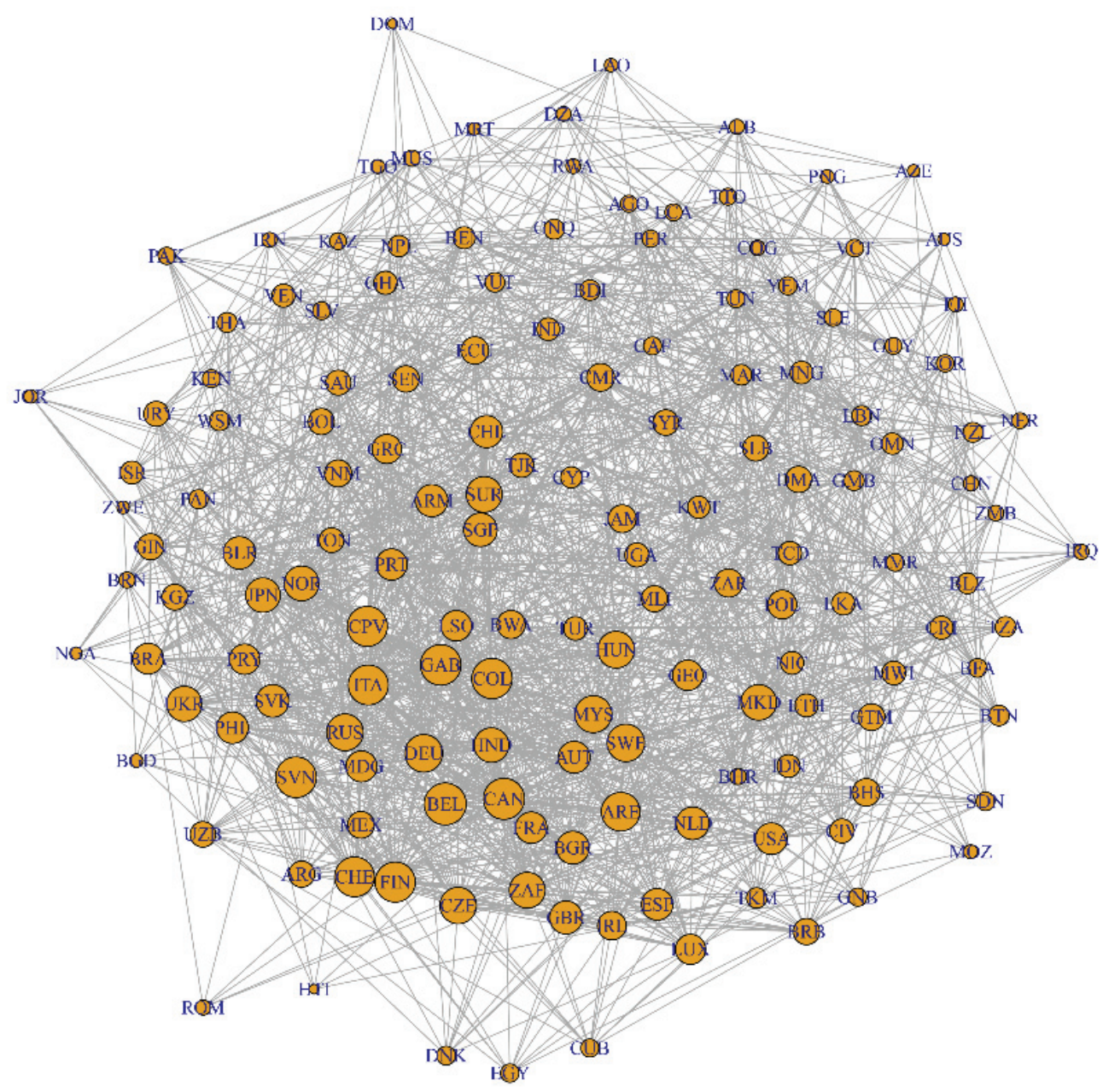

Source: Own calculation 
Figure 7: Sub-networks of recessions in G7 countries and China
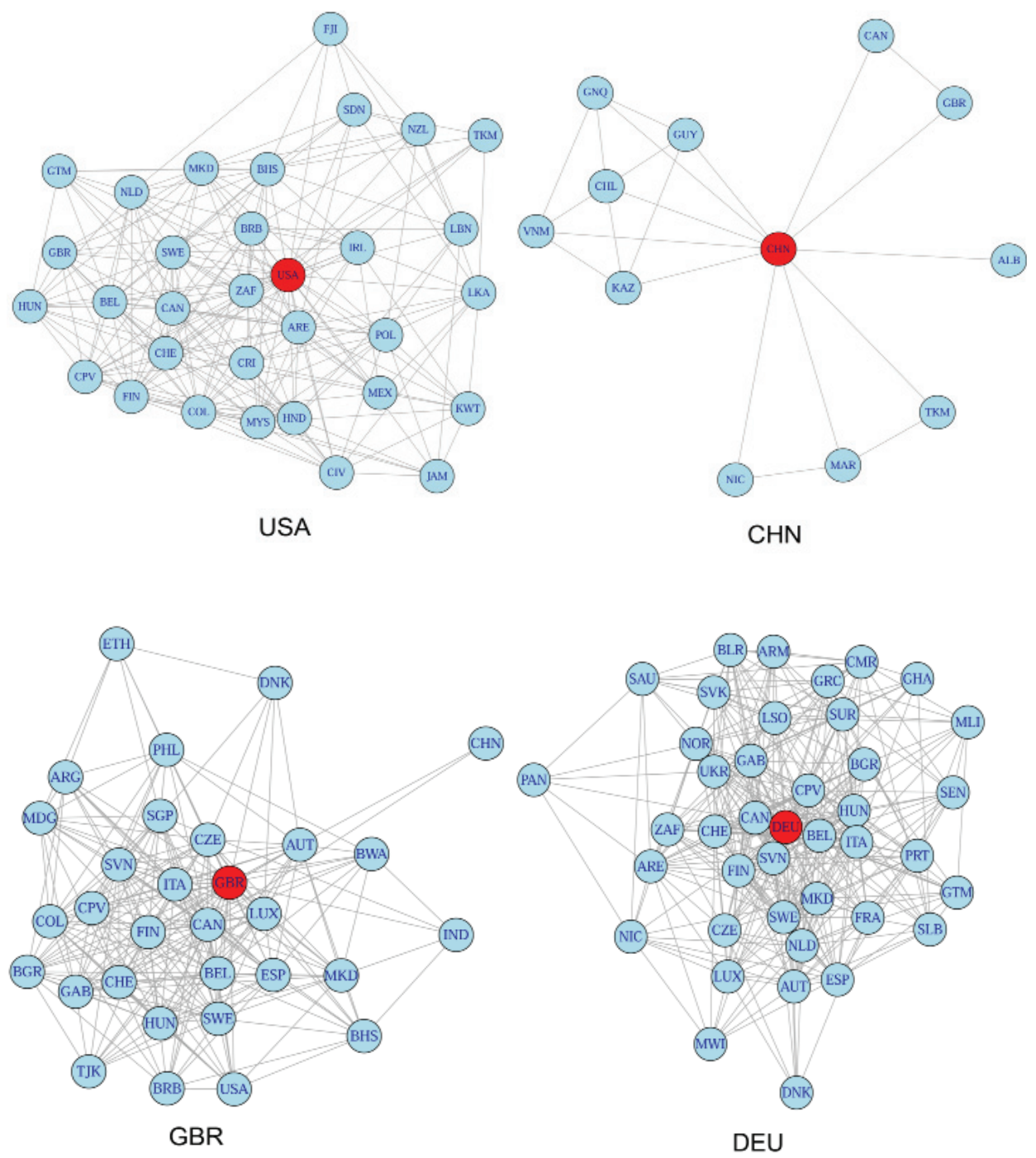


\section{Figure 7: Continuation}

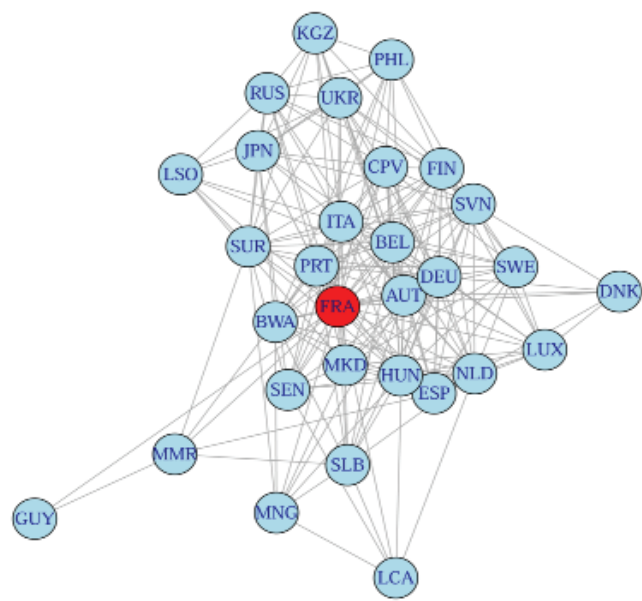

FRA

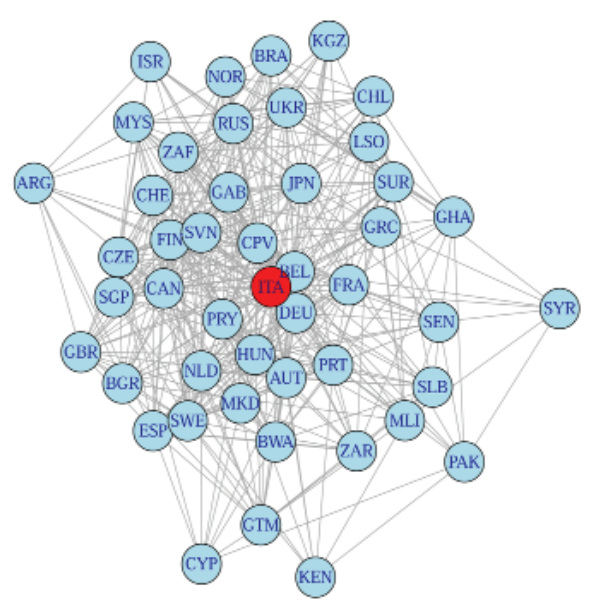

ITA
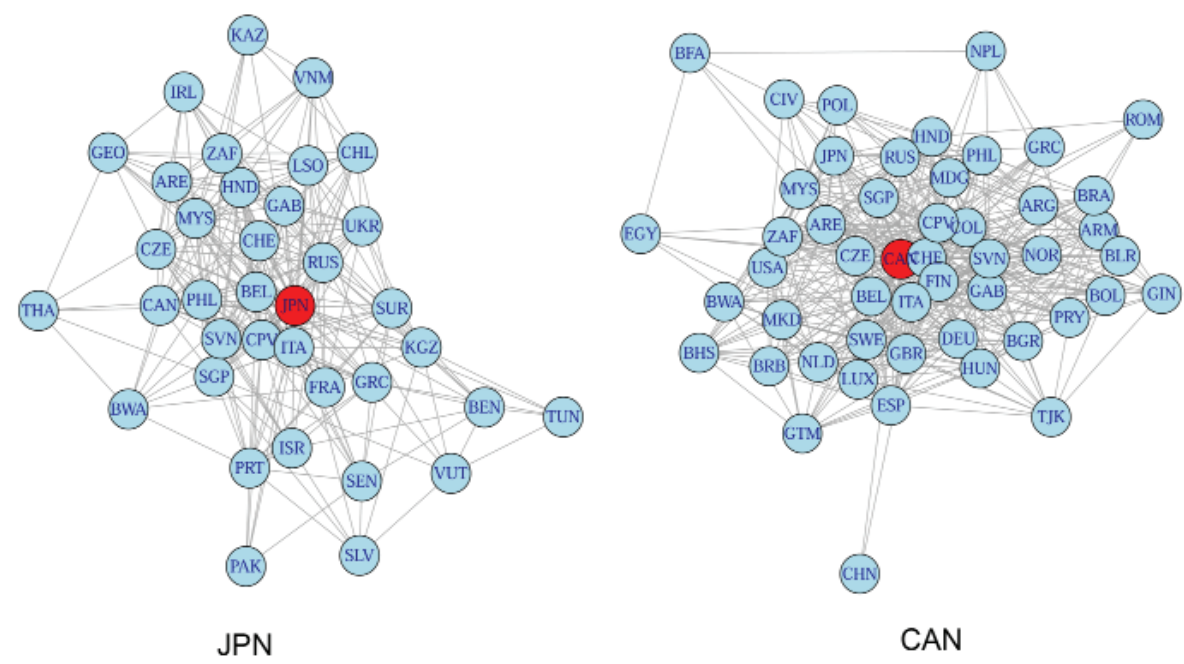

Source: Own calculation

Furthermore, the density of the entire network and the densities of the sub-networks of the G7 countries and China are calculated. The calculation results show that the overall network density is 0.16 , while the densities of the sub-networks of the G7 countries and China are significantly higher than the overall network density. Among 
them, the United Kingdom exhibits the largest sub-network density of 0.51 and China exhibits the smallest sub-network density of 0.33 . The sub-network densities of the United States, France, Germany, Italy, Canada and Japan are 0.45, 0.49, 0.45, 0.43, 0.40 and 0.42 , respectively. To provide an illustration of the densities of the sub-networks, Figure 7 shows the sub-network maps of the eight countries. The densities of the sub-networks of the G7 countries and China are more than twice that of the entire network, indicating that the recessions in these countries have wider influence scope compared to other countries in the network.

\section{Discussion}

This study identified the characteristics of all the historical recessions since 1980 in the 153 countries using the turning point method and analysed the distribution of the $\triangle \mathrm{GDP}$ in these countries during the recession introduced by the COVID-19 pandemic using Monte Carlo simulation. This study contributes to existing research in two aspects. Firstly, it provides a description of the evolution path of the whole recession induced by the COIVD-19 pandemic. Secondly, it explains the distribution characteristics of the $\triangle$ GDP during the recession from a statistical probability perspective.

In terms of the recession amplitude, the results of this study indicate that the trough of this pandemic-induced recession occurs in 2020 and the global $\Delta$ GDP in 2020 is most likely to be within the range from $-2.63 \%$ to $1.20 \%$. The mean of the calculated average $\Delta$ GDP in the 153 major countries shows a 4.50 p.p. decline from $3.30 \%$ in 2019 to $-1.16 \%$ in 2020. The results also show that the lower quartiles of the simulated $\Delta$ GDP of all the G7 countries fall to negative in 2020 . The interquartile ranges of the simulated $\Delta$ GDP of all the G7 countries in 2020 vary from $-3.28 \%$ to $0.95 \%$, whereas the interquartile range of the simulated $\Delta \mathrm{GDP}$ of China in 2020 varies from $3.97 \%$ to $5.82 \%$. The calculated recession amplitudes in the major economies of the G7 countries and China range from $1.67 \%$ to $3.80 \%$. The unprecedented COVID-19 pandemic has brought sudden extreme shocks to the world economy in various respects and has exerted a more negative impact on global economic activities in the first half of 2020 than anticipated; thus, the pandemicinduced recession is most likely to grow to be among the most severe ones in history. Compared to the results of this study, the estimates of the International Monetary Fund (IMF) show a more pessimistic attitude and indicate a more severe recession. Up until mid-2020, the International Monetary Fund had consecutively lowered its global growth forecast for 2020 and its latest estimates, released in June 2020, predicted that the global economy would fall by $4.9 \%$ in 2020 , with a recession amplitude of approximately $8 \%$ (IMF, 2020). The $\Delta$ GDP in all the G7 countries were projected to fall below $-5 \%$ 
in 2020, with the lowest of $-12.5 \%$ shown in France, and the $\Delta$ GDP in China to $1 \%$, with recession amplitudes ranging from $5.1 \%$ to $14 \%$. Although there exist some differences between the estimates from this study and those from the IMF, both of the estimates indicate that the current recession induced by the COVID-19 pandemic will emerge as one of the most severe recessions in recent history, and this study further explains the most likely range of this recession from a statistical probability perspective. As for the duration of this recession, the IMF report only indicates that the global economy will begin to recover in 2021 but does not provide further description of the whole recession process. In this study, we outlined the whole process of both recession and recovery phases using Monte Carlo simulations based on the characteristics of historical recessions since 1980. The results suggest that the trough of the recession will occur in 2020 at a global level and in most countries, and most economies will enter the recovery phase in 2021 and return to their pre-crisis levels around 2023.

Furthermore, this study constructed a co-movement network of global recessions based on an analysis of the concordance between historical recessions in 153 countries. The results show that the economic recessions in these countries present a high degree of co-movement and constitute a small-world network, within which the recessions in the G7 countries and China exhibit a wider influence scope. These features of the co-movement network make the recession in one country easily transmitted to other countries, thereby impacting on the economies of other related countries. So far, due to its highly contagious nature, the COVID-19 pandemic has expanded to more than 200 countries and pushed most countries into economic hardship at the same time, resulting in a large-scale global recession. In addition, as a strong co-movement relationship exists between the recessions in countries around the world, when the recessions are synchronized across the countries, the effects can be further amplified through international trade and financial linkages, adding to the hardship of the already struggling economy at a global level.

\section{Conclusion}

The world was an unusual place in 2020 due to the outbreak of the COVID-19 pandemic. As an unprecedented public health crisis, the pandemic has severely impacted on the global economy at the same time. The purpose of this study is to investigate the economic impacts of the recession induced by the COVID-19 pandemic by estimating the depth, duration and influence scope of the recession in 153 countries. However, the lack of historical benchmarks makes it difficult to predict the economic impacts of the COVID-19 crisis. Thus, we employed Monte Carlo simulation to describe the depth and duration of the recession based on the characteristics of all the historical recessions in recent history. 
The simulation results show that the global $\triangle \mathrm{GDP}$ is likely to drop into a trough ranging from $-2.63 \%$ to $1.20 \%$ in 2020 with an estimated average recession amplitude of 4.50 p.p. and the mean of the average $\Delta$ GDP in 153 major countries is projected to recover to the pre-crisis level of $3.29 \%$ in 2023 . Similar to the pattern presented in the global $\Delta \mathrm{GDP}$ during the recession, the $\Delta \mathrm{GDP}$ in most of the G7 countries and China decline into a trough in 2020 and recover to the pre-crisis levels in 2023, with recession amplitudes ranging most likely from $1.67 \%$ to $3.80 \%$. The results of the calculated co-movement network of global recessions indicate that the economic recession in an individual country is easily transmitted to other countries and that the current pandemic-induced recession which hit the G7 countries and China almost simultaneously will be a recession on a global scale. Thus, no individual country can recover from the pandemic-induced recession independently and the world should build allies and conduct coordinated actions to deal with the recession. The results of this study could help governments to better understand the economic impacts of the pandemic-induced recession and make proper policies to alleviate the impacts of the recession and reboot the economy.

The limitation of this study lies in the highly uncertain nature of the pandemic. We simulated the possible outcomes of the recession induced by the COVID-19 pandemic based on the characteristics of all the historical recessions since 1980. However, this pandemic emerges as a rare joint public health and economic crisis. The high degree of uncertainty embedded in the pandemic makes it possible to lead to a recession that is tremendously different from all the previous ones.

\section{References}

Baldwin, R., Weder di Mauro, B. (2020). Introduction, in Baldwin, R., Weder di Mauro, B., eds., Mitigating the COVID Economic Crisis: Act Fast and Do Whatever It Takes. London: CEPR Press, pp. 1-24.

Beck, T. (2020). Finance in the Times of COVID-19: What Next?, in Baldwin, R., Weder di Mauro, B., eds., Mitigating the COVID Economic Crisis: Act Fast and Do Whatever It Takes. London: CEPR Press, pp. 179-184.

Burns, A. F., Mitchell, W. C. (1946). Measuring Business Cycles. NBER Book Series Studies in Business Cycle. New York: National Bureau of Economic Research.

Cardarelli, R., Elekdag, S., Lall, S. (2011). Financial Stress and Economic Contractions. Journal of Financial Stability, 7(2), 78-97, http://doi.org/10.1016/j.jfs.2010.01.005

Carstensen, K., Heinrich, M., Reif, M., et al. (2020). Predicting Ordinary and Severe Recessions with a Three-state Markov-switching Dynamic Factor Model: An Application to the German Business Cycle. International Journal of Forecasting, 36(3), 829-850, http://doi.org/10.1016/j.ijforecast.2019.09.005 
Claessens, S., Kose, M. A., Terrones, M. E. (2009). What Happens during Recessions, Crunches and Busts? Economic Policy, 24(60), 653-700, http://doi. org/10.1111/j.1468-0327.2009.00231.x

da Silva, M. F., Pereira, É. J. D. A. L., da Silva Filho, A. M., et al. (2016). Quantifying the Contagion Effect of the 2008 Financial Crisis between the G7 Countries (by GDP Nominal). Physica A: Statistical Mechanics and its Applications, 453, 1-8, http://doi.org/10.1016/j. physa.2016.01.099

Dewandaru, G., Masih, R., Masih, M. (2018). Unraveling the Financial Contagion in European Stock Markets during Financial Crises: Multi-Timescale Analysis. Emerging Markets Finance and Trade, 54(4), 859-880, http://doi.org/10.1080/1540496X.2016.1266614

Dimitras, A. I., Kyriakou, M. I., latridis, G. (2015). Financial Crisis, GDP Variation and Earnings Management in Europe. Research in International Business and Finance, 34, 338-354, http://doi.org/ 10.1016/j.ribaf.2015.02.017

Drechsel, K., Scheufele, R. (2012). The Performance of Short-term Forecasts of the German Economy before and during the 2008/2009 Recession. International Journal of Forecasting, 28(2), 428-445, http://doi.org/10.1016/j.ijforecast.2011.04.003

Fernandes, N. (2020). Economic Effects of Coronavirus Outbreak (COVID-19) on the World Economy. University of Navarra and European Corporate Governance Institute, IESE Business School. Working Paper No. WP-1240-E, https://doi.org/10.2139/ssrn.3557504

Frankel, J., Saravelos, G. (2012). Can Leading Indicators Assess Country Vulnerability? Evidence from the 2008-09 Global Financial Crisis. Journal of International Economics, 87(2), 216-231, http://doi.org/10.1016/j.jinteco.2011.12.009

Galí, J. (2020). Helicopter Money: The Time Is Now, in Baldwin, R., Weder di Mauro, B., eds., Mitigating the COVID Economic Crisis: Act Fast and Do Whatever It Takes. London: CEPR Press, pp. 57-62.

Gascon, C. S. (2009). The Current Recession: How Bad Is It? St. Louis: Federal Reserve Bank of St. Louis. Economic SYNOPSES [Retrieved 2020-05-10] Available at: https://files. stlouisfed.org/files/htdocs/publications/es/09/ES0904.pdf

Gopinath, G. (2020). Limiting the Economic Fallout of the Coronavirus with Large Targeted Policies, in Baldwin, R., Weder di Mauro, B., eds., Mitigating the COVID Economic Crisis: Act Fast and Do Whatever It Takes. London: CEPR Press, pp.41-48.

Gourinchas, P. O. (2020). Flattening the Pandemic and Recession Curves, in Baldwin, R., Weder di Mauro, B., eds., Mitigating the COVID Economic Crisis: Act Fast and Do Whatever It Takes. London: CEPR Press, pp. 31-40.

Harding, D., Pagan, A. (2002). Dissecting the Cycle: A Methodological Investigation. Journal of Monetary Economics, 49(2), 365-381, http://doi.org/10.1016/S0304-3932(01)00108-8

Harding, D., Pagan, A. (2006). Synchronization of Cycles. Journal of Econometrics, 132(1), 59-79, https://doi.org/10.1016/j.jeconom.2005.01.023

International Monetary Fund (2020). World Economic Outlook Report, June 2020: A Crisis Like No Others, An Uncertain Recovery. Washington, DC: International Monetary Fund. 
Kim, B. H., Kim, H., Lee, B. S. (2015). Spillover Effects of the U.S. Financial Crisis on Financial Markets in Emerging Asian Countries. International Review of Economics \& Finance, 39, 192-210, https://doi.org/10.1016/j.iref.2015.04.005

Makridis, C., Hartley, J. (2020). The Cost of COVID-19: A Rough Estimate of the 2020 US GDP Impact. Special Edition Policy Brief, http://doi.org/10.2139/ssrn.3570731

Mann, C. L. (2020). Real and Financial Lenses to Assess the Economic Consequences of COVID-19, in Baldwin, R., Weder di Mauro, B., eds., Economics in the Time of COVID-19. London: CEPR Press, pp. 81-85.

Mazurek, J., Mielcová, E. (2013). The Evaluation of Economic Recession Magnitude: Introduction and Application. Prague Economic Papers, 22(2), 182-205, http://doi. org/10.18267/j.pep.447

McDermott, C. J., Cashin, P. A., Scott, A. M. (1999). The Myth of Co-Moving Commodity Prices. Bank of New Zealand. Discussion Paper No. G99/9, http://doi.org/10.2139/ssrn.321381

Odendahl, C., Springford, J. (2020). Bold Policies Needed to Counter the Coronavirus Recession, in Baldwin, R., Weder di Mauro, B., eds., Mitigating the COVID Economic Crisis: Act Fast and Do Whatever It Takes. London: CEPR Press, pp. 135-150.

Ozili, P. K., Arun, T. (2020). Spillover of COVID-19: Impact on the Global Economy. Central Bank of Nigeria and University of Essex. Working Paper No. 3562570, http://doi.org/10.2139/ ssrn. 3562570

Panizza, U. (2020). 17 Europe's Ground Zero, in Baldwin, R., Weder di Mauro, B., ed., Mitigating the COVID Economic Crisis: Act Fast and Do Whatever It Takes. London: CEPR Press, pp.151-166.

Ramelli, S., Wagner, A. F. (2020). Feverish Stock Price Reactions to COVID-19. University of Zurich. Swiss Finance Institute Research Paper No. 20-12, http://doi.org/10.2139/ssrn.3550274

Roberts, M. C. (2009). Duration and Characteristics of Metal Price Cycles. Resources Policy, 34(3), 87-102, http://doi.org/10.1016/j.resourpol.2009.02.001

Rossen, A. (2015). What Are Metal Prices Like? Co-movement, Price Cycles and Long-run Trends. Resources Policy, 45, 255-276, http://doi.org/10.1016/j.resourpol.2015.06.002

Weder di Mauro, B. (2020). Macroeconomics of the Flu, in Baldwin, R., Weder di Mauro, B., eds., Economics in the Time of COVID-19. London: CEPR Press, pp. 31-37.

World Bank Database (2020). Washington, D.C.: The World Bank [Retrieved 2020-03-05] Available at: https://databank.worldbank.org/home.aspx 